\title{
Práticas de Linguagem como Mtividade Social: - Lingüista Frente ao Desafio de Apreender a Complexidade dos Diferentes Modos de Mabitar o Mundo
}

\author{
Bruno DEUSDARÁ \\ (CEFET-RJ / PG-UERJ) \\ Maria Cristina GIORGI \\ (CEFET-RJ / PG UFF)
}

\begin{abstract}
Resumo: Problematizamos a especificidade do trabalho do lingüista, frente ao desafio de apreender a complexidade dos diferentes modos de ser, pensar, agir e sentir no mundo. Para tal, privilegiamos as reflexões em um ponto de vista enunciativo, segundo o qual as práticas de linguagem constituem atividade social, com enfoque na centralidade da noção de gênero do discurso (BAKHTIN, 2000). Analisamos o percurso de pesquisas tematizando a produção de sentido sobre o trabalho docente. Destacamos as reconfigurações propostas pelo referencial discursivo nas fronteiras disciplinares da Lingüística, em intercâmbio constante com diferentes campos das ciências humanas. Palavras-chave: Análise do Discurso, abordagem enunciativa, gêneros do discurso.
\end{abstract}

\begin{abstract}
We see the specificity of a linguist's work as an issue to be raised in the light of the challenge faced when learning the complexity of different ways of being, thinking, acting and feeling in the world. In order to accomplish such study, we concentrate on considerations within an enunciative perspective - which claims that language practices constitute a social activity - and we focus on the centrality of the concept of discourse genre (BAKHTIN, 2000). We carry out a review of researches whose theme is the production of meaning when it comes to teaching output. We highlight the reconfigurations suggested by the discourse referential in the disciplinary boundaries of Linguistics, in a constant exchange with different fields of human sciences.
\end{abstract}

Keywords: Discourse Analysis, enunciative approach, discourse genres. 


\section{Considerações iniciais}

No presente artigo, elegemos como problemática a ser desenvolvida os debates em torno da definição de um objeto de estudo das ciências da linguagem, a partir das contribuições oferecidas por uma abordagem enunciativa. Trata-se de problemática que, embora tenha sido alvo de discussões que já consolidaram algumas possibilidades de caminhos a serem percorridos, permanece latente, suscitando polêmicas de diferentes ordens. Ressaltamos assim que, em termos gerais, os esforços empreendidos em torno da referida problemática têm-se caracterizado pela definição de um objeto específico, cujo recorte delimitaria as particularidades do trabalho do lingüista. Atualmente, é o próprio referencial que assegurou a instituição de fronteiras disciplinares supostamente tão evidentes e, por conseqüência, garantiu a constituição dos especialistas que se encontra em discussão.

Considerando a trajetória mais recente de pesquisas no âmbito dos estudos do discurso, destacam-se sobremaneira os diálogos produzidos entre as ciências da linguagem e os referenciais teóricos de disciplinas como a História, a Psicologia Social, os Estudos Culturais, as Ciências do Trabalho, as Ciências Política e Econômica, entre outras. Tais diálogos sustentam-se em consonância com a tentativa de compreender, segundo pontos de vista distintos, fenômenos que envolvam as formas de organização social, econômica e do trabalho, as diferentes dimensões da atividade cultural e política, abrangendo, portanto, a complexidade dos modos de agir, pensar, sentir e ser no mundo contemporâneo.

Os fenômenos mencionados anteriormente estão longe de configurar um território privativo dos estudos da linguagem, haja vista sua complexidade motivadora de múltiplas formas de entrada para análise. Nesse cenário contemporâneo de reflexões, caberia questionar acerca da delimitação dos fenômenos a serem postos em análise pelo lingüista, bem como da especificidade do tratamento dado por ele aos fenômenos em tela. Assim sendo, algumas questões emergem de maneira contundente no cotidiano de pesquisas em perspectiva discursiva: em que medida ainda é possível sustentar que, ao discutir fenômenos vinculados a problemáticas como a da subjetividade, estamos tomando emprestados conceitos correspondentes a outras disciplinas? Ou ainda, de que modo nos mantemos vinculados a um 
dado esquadrinhamento dos saberes, hegemônico no ocidente até meados do século XX, ao julgar que discutir o problema da subjetividade, por exemplo, significa um cruzamento das fronteiras disciplinares que garantem um território próprio do lingüista?

Tal esquadrinhamento dos saberes corresponde a recortes constituídos na tradição ocidental e que ganharam consistência na configuração moderna das ciências. O regime de produção de saberes científicos organiza-se no sentido de reivindicar legitimidade social a partir de procedimentos que garantiriam objetividade e universalidade. A objetividade afastaria aspectos da ordem do intuitivo e das incertezas. Já a universalidade esforça-se por encontrar regularidades nos escombros dos eventos circunstanciais. Os saberes científicos seriam aqueles provenientes da preponderância da lógica racional asséptica em detrimento de outras lógicas, que, a partir de então, inspirariam desconfiança e inconsistência (ROCHA, 1998).

Nesse quadro, a confiabilidade de tais saberes se asseguraria na possibilidade de comprovação experimental. Os conhecimentos cientificamente comprovados são aqueles que se repetem independente das circunstâncias da experiência. O esforço do especialista caracterizase então por desenvolver e aprimorar critérios, normas e procedimentos capazes de extrair conhecimento formal para além dos acasos (ROCHA, 1998).

Vemos assim que a especificidade do lingüista no momento atual não mais se refere à lógica dos especialismos, que assegura e reproduz os recortes oriundos da paisagem moderna das ciências. A especificidade a que nos referimos não mais estaria vinculada a um projeto de acúmulo de saberes, buscando alcançar um estado de conhecimento pleno do mundo. Nosso esforço no âmbito deste artigo residiria então em oferecer alguns aspectos que nos permitam um delineamento dessa especificidade, a partir de uma determinada configuração dos fenômenos a serem privilegiados pelos estudos do discurso, sobretudo segundo uma abordagem enunciativa.

A esse respeito, a citação a seguir de Bakhtin soa-nos como um desafio, senão vejamos:

Problema do texto nas ciências humanas. As ciências humanas não se referem a um objeto mudo ou a um fenômeno natural, referemse ao homem em sua especificidade. O homem tem a especificidade 
de expressar-se sempre (falar), ou seja, de criar um texto (ainda que potencial). Quando o homem é estudado fora do texto e independentemente do texto, já não se trata de ciências humanas (mas de anatomia, de fisiologia humana, etc.). (BAKHTIN, 2000, p. 334)

Assim sendo, nos limites propostos para esta nossa discussão, pretendemos dar visibilidade a uma entrada conceitual - os gêneros do discurso - que se tem mostrado produtiva por contribuir com um desafio importante no âmbito das ciências humanas e que se sintetiza na citação desafiadora de Bakhtin, qual seja a de pensar a linguagem como parte das ações humanas no mundo. Assim, seria preciso salientar que cada uma das disciplinas que compõem as chamadas ciências humanas contribuiria não com o fato de esforçar-se para delimitar seu objeto próprio, mas sim oferecendo diferentes possibilidades de apreensão do agir do homem no mundo.

Com efeito, o que está em foco, no âmbito dos estudos da linguagem, não é o texto como realidade em si, dotado de relativa autonomia frente ao contexto em que fora produzido. Essa compreensão tem contribuído para imaginar que a linguagem se restringe a representar o mundo dado previamente. Dessa forma, apaga-se das pesquisas uma investigação importante no sentido de compreender, a partir das formas da linguagem, suas condições de possibilidade de emergência.

\section{Desmanchando os contornos de uma paisagem disciplinar}

Neste item, tratamos de pôr em diálogo referenciais de origens distintas, a partir dos quais é possível sustentar polêmicas que nos permitam constituir dispositivos de análise que façam frente a uma lógica de disciplinamento dos saberes. Nesse contexto, cabe compreender os diferentes modos de acordo com os quais tem sido possível construir uma narrativa em torno da história dos regimes de produção de conhecimento.

A constituição de um percurso em que se assentariam as diferentes formas de produção de saberes, projeto que se circunscreveria nos marcos de uma ciência como a epistemologia, temse organizado, de modo mais geral, a partir de uma lógica de 
continuidade. Considerando como ferramenta categorias tais quais as de tradição, influência e mentalidade, a história das ciências tem-se conformado, em grande medida, à narrativa que procura delimitar a mentalidade de uma época, por exemplo, pondo o foco nas semelhanças entre trajetórias que seriam contemporâneas, de acordo com os cortes temporais determinados. Ou ainda, trata-se de um esforço de mapear, ao longo de um dado percurso da produção de saberes, movimentos, ao menos supostamente, convergentes que acabariam por apontar influências de certos autores sobre outros, configurando assim uma trajetória retilínea de uma tradição.

Ao lado dessa lógica da continuidade na constituição de um percurso das ciências, há uma outra, aquela que daria ênfase às rupturas, ou descontinuidades. A produção de saberes opera, portanto, não através de permanências, mas considera que, sob todas as formas de reivindicar tradições, influências, residiriam "acertos”, torções, desvios de rotas, enfim, um conjunto bastante diversificado de fenômenos que nos evidenciaria a necessidade de, no lugar de buscar as continuidades reivindicadas, considerar a emergência do próprio discurso científico como um acontecimento. Esse acontecimento discursivo que se caracterizaria pela emergência dos enunciados não se enquadraria nos lugares previstos e bem arrumados dos percursos lineares, mas comporia certo jogo estratégico.

A esse respeito, Foucault afirma:

É preciso estar pronto para acolher cada momento do discurso em sua irrupção de acontecimentos, nessa pontualidade em que aparece e nessa dispersão temporal que lhe permite ser repetido, sabido, esquecido, transformado, apagado até nos menores traços, escondido bem longe de todos os olhares, na poeira dos livros. (FOUCAULT, 2004, p. 28)

Ainda segundo Foucault (2002), essa lógica da continuidade em que se assentam os estudos em história das ciências corresponderia às operações de disciplinamento dos saberes ativadas ao longo do século XVIII. Trata-se de quatro operações que teriam precedido à organização interna de cada disciplina. Assim, uma disciplina se constituiria a partir de uma operação de seleção, que distinguiria os saberes reconhecidos como válidos a partir de seus critérios, de outros, 
que passariam a configurar regiões de não-saberes, ou ainda de saberes considerados falsos em relação à seleção. Os saberes selecionados passariam por operações de normalização, promovendo a homogeneização dos conteúdos de uma disciplina; e de hierarquização, instituindo níveis de incidência desses saberes, certo encadeamento entre eles; e de centralização, fazendo aparecer aparelhos a partir dos quais se autorizaria a produção de saberes. Essas quatro operações se conformam em um regime de disciplinamento de todo o tecido social, com a emergência de instituições disciplinares.

Com efeito, é preciso considerar que a busca por um objeto particular da Lingǘstica enquadra-se no modelo das operações de seleção, normalização, hierarquização e centralização dos saberes. Esse modelo, embora não deixe de reconhecer que historiadores, psicólogos, cientistas sociais, estatísticos, entre outros profissionais, exercem em seu ofício um trabalho sobre a linguagem, acaba por propor a legitimidade de um profissional, o lingüista, a quem seria dada a palavra final acerca dos saberes sobre a língua. Parece caber a nós mesmos certa reflexão que nos permita fazer derivar esse modelo, que nos autoriza e convoca a falar sobre a língua... E apenas sobre ela!

Cabe-nos, nesse sentido, pôr em suspenso as unidades com as quais estamos habituados a trabalhar, já que elas parecem corresponder a certa evidência de que haveria fenômenos estritamente lingüísticos. No âmbito dos estudos do discurso, tal operação nos levaria a problematizar o tratamento que temos tradicionalmente conferido aos textos. Esse tratamento tem estado, em certas circunstâncias, fortemente marcado por uma lógica dicotômica que apostaria na cisão entre fenômenos da ordem do lingüístico e de outra ordem, que estariam, ao menos supostamente, no seu entorno, chamados, portanto, de extralingüísticos.

Parece-nos ser necessária a apropriação por parte do lingüista de um referencial que potencialize a constituição de um campo de polêmicas que nos permita ir além dos cortes e das fronteiras que se mostrem naturalizadas. É preciso assim recorrer a instrumentais que nos façam duvidar da autonomia relativa do texto frente aos seus contextos de produção e circulação. Cada vez mais, tem sido possível pensar o texto como materialidade lacunar, pistas fragmentárias de práticas sociais que ganham consistência em registros diversos, entre eles, a linguagem. Pode-se assim pensar nas práticas de linguagem como entrada possível para a apreensão da complexidade da ação humana. 
Entre as ferramentas possíveis para tal empreendimento, Bakhtin (2000) parece-nos um referencial potente, já que o referido autor propõe um campo de investigações que se movimenta nas fronteiras entre as diferentes disciplinas que constituem as ciências humanas, com ênfase para o que, além dos especialismos, possa emergir como aproximação possível entre elas. Diante desse propósito, Bakhtin torna-se um importante aliado para pensar o texto não como realidade em si, mas como dimensão das ações humanas que ganha materialidade por meio de práticas de linguagem.

Essas reflexões assumem lugar de destaque no cotidiano do pesquisador no âmbito dos estudos da linguagem, uma vez que um dos desafios inerentes ao seu ofício refere-se ao desenvolvimento de ferramentas e estratégias de "recortes" de textos. Trata-se de questão difícil, diante da qual é preciso rejeitar um efeito negativo que apontaria os textos como realidades relativamente autônomas frente a seus contextos, prontas a serem colhidas pelos estudiosos da linguagem.

Vejamos, portanto, de que modo a noção de texto vai se configurando de acordo com Bakhtin (2000). Para ele, o texto configuraria certa atualização de uma dinâmica em que se entrelaçariam fenômenos da ordem do previsível, provenientes de um campo de regularidades que seria a língua, e os da ordem do imprevisível, que remeteriam aos laços indissolúveis entre o texto e as condições de possibilidade de emergência e circulação. A cada vez que um texto é relido, deslocado de seus contextos tidos como habituais, entre outros aspectos, apenas aparentemente teríamos um mesmo texto, diante de uma mesma leitura, fazendo circular os mesmos sentidos. Segundo o referencial que está sendo privilegiado neste artigo, é preciso dizer que, por exemplo, ao retirar uma notícia de jornal e afixá-la em mural escolar, outras expectativas de leitura instituem-se, outras relações se estabelecem entre os co-enunciadores envolvidos nessa interação. Dessa forma, é possível sustentar que os sentidos se compõem sempre de outro modo. Não obstante as permanências de ordem variada, um texto produz-se como singularização de processos sócio-históricos, culturais, políticos que nunca se repetem.

Cada texto pressupõe um sistema compreensível para todos (convencional, dentro de uma dada coletividade) - uma língua (ainda que seja a língua da arte). Se por trás do texto não há uma língua, já 
não se trata de um texto, mas de um fenômeno natural (não pertencente à esfera do signo); por exemplo, uma combinação de gritos e gemidos, desprovida de reprodutibilidade lingüística (própria do signo). [...]

Assim, por trás de todo texto, encontra-se o sistema da língua; no texto, corresponde-lhe tudo quanto é repetitivo e reproduzível, tudo quanto pode existir fora do texto. Porém, ao mesmo tempo, cada texto (em sua qualidade de enunciado) é individual, único e irreproduzível, sendo nisso que reside seu sentido (seu desígnio, aquele para o qual foi criado). (BAKHTIN, 2000, p. 331)

Paradoxalmente, o texto é dimensão em que se atualiza uma realidade convencional, anterior a ele, como condição de sua existência e circulação, ao mesmo tempo em que só tem sentido por constituirse através de processos de singularização. Ou seja, os movimentos de sentidos próprios ao texto transitam entre a repetição e a diferença.

Desse modo, apenas aparentemente teríamos a repetição de um texto, já que mesmo a reimpressão - em que se mantém a forma tipográfica do texto, dando aparência de um processo de reprodução absoluto - dialogaria de maneira distinta com o novo contexto. Assim, a aparente reprodução de um texto, seja por releitura, por citação, seja por qualquer outra forma, "é um acontecimento novo, irreproduzível na vida do texto, é um novo elo na cadeia histórica da comunicação verbal" (BAKHTIN, 2000, p. 332).

No próximo item, pretendemos oferecer ao leitor discussões acerca da sistematização proposta por Bakhtin em torno da problemática dos diferentes modos de articulação entre os textos e seus contextos de produção e circulação.

2 Trajetórias para compreensão do trabalho docente: a noção de gênero do discurso e possibilidades de encaminhamentos

No item anterior, apresentamos algumas discussões acerca dos processos de disciplinamento dos saberes e a correlata produção de um lugar de especialista, ao qual é conferida a legitimidade de falar, em última instância, sobre dado objeto de estudo. Desse modo, relacionamos o projeto de constituição de um objeto particular para as ciências da linguagem a essa lógica de disciplinamento que selecionou, 
normalizou, hierarquizou e centralizou os saberes em consonância com a emergência das instituições disciplinares, entre os séculos XVIII e XIX.

Com efeito, a dicotomia clássica entre o lingüístico e o extralingüístico parece oferecer evidências à necessidade de emergência de uma disciplina e, por conseqüência, de um profissional a quem se pudesse confiar o estudo do lingüístico, em sentido estrito.

Neste item, explicitaremos a noção de gênero do discurso, com o objetivo de evidenciar que dimensão das práticas de linguagem se pretende apreender ao adotar tal perspectiva. Ao propor uma definição para os gêneros do discurso, ele dirá: “Todas as esferas da atividade humana, por mais variadas que sejam, estão sempre relacionadas com a utilização da língua", e, em seguida, acrescenta: "A utilização da língua efetua-se em forma de enunciados (orais e escritos), concretos e únicos, que emanam dos integrantes duma ou doutra esfera da atividade humana" (BAKHTIN, 2000, p. 280).

Assim, quando analisamos os gêneros do discurso estamos diante de "tipos relativamente estáveis de enunciados" (BAKHTIN, 2000, p. 280). Com efeito, tal definição de gênero do discurso pretende afastar uma outra, mais próxima ao que, desde a Antigüidade grega.

Quando analisamos os gêneros do discurso, não nos deparamos com a estrutura interna de um texto ou de um conjunto de textos, antes entramos em um diálogo com valores e sentidos que podem circular em um tempo e um lugar determinados.

Assim, cada enunciado deve ser compreendido como produto social e lingüístico, como portador de valores culturais, humanos, ideológicos, estéticos e morais, como reflexo de uma época concreta e como possibilidade de comunicação com seres próximos ou distantes no tempo e no espaço, resultados de atividades lingüísticas, com pistas que representam conhecimento acumulado de ambas as partes da interlocução. (GIORGI; DEUSDARÁ, 2007, p. 15)

Ao se confrontar com a singularidade de cada situação de enunciação, Bakhtin elabora o conceito de gêneros do discurso. É essa relativa estabilidade que fundamentará a teoria do enunciado concreto atribuída ao referido autor. 
Em oposição aos modelos informacionais em que o locutor assume uma posição ativa, como emissor de uma dada mensagem, enquanto o interlocutor apenas a recebe, a partir da noção de gênero do discurso, compreende-se a comunicação verbal como espaço de co-produção entre os parceiros, ambos, locutor e interlocutor, em "atitude responsiva ativa."

[...] o próprio locutor como tal é, em certo grau, um respondente, pois não é o primeiro locutor, que rompe pela primeira vez o eterno silêncio de um mundo mudo, e pressupõe não só a existência do sistema da língua que utiliza, mas também a existência dos enunciados anteriores - emanantes dele mesmo ou do outro - aos quais seu próprio enunciado está vinculado por algum tipo de relação. (BAKHTIN, 2000, p. 291)

Locutor e interlocutor, para nos utilizarmos aqui da terminologia de Bakhtin, respondem não apenas um ao outro, mas a enunciadores anteriores à situação concreta em que se encontram; da mesma forma, de algum modo, seus enunciados são antecipações de questionamentos ainda por serem realizados. O sentido produz-se exatamente nessa relação com enunciados anteriores e posteriores e não em formas lingüísticas que remetem ao sistema da língua.

Nos tópicos que seguem, oferecemos ao leitor uma breve contextualização das trajetórias das pesquisas que, de algum modo, contemplaram certos aspectos das discussões elaboradas anteriormente. Acrescentaríamos que ambas as pesquisas têm motivação em nossa prática profissional como professores de Língua Portuguesa e Língua Estrangeira, em instituições públicas de Educação Básica. Nessas pesquisas, o desafio é problematizar as estratégias de produção de saberes outros que, igualmente àqueles inerentes às atividades realizadas em sala de aula, supõem-se necessários ao magistério.

\subsection{O mural da sala de professores como dispositivo de produção de subjetividade}

$\mathrm{Na}$ pesquisa a ser apresentada neste item, o ponto de partida considerado reside na evidência de que o professor trabalha para além dos encontros com alunos, nas situações de sala de aula. Desse modo, 
a referida pesquisa optou por uma observação empírica, elegendo a sala de professores de uma escola de rede pública estadual como espaço-tempo das interações analisadas. Tal opção sustenta-se na noção ampliada de "situação de trabalho" (ROCHA; DAHER; SANT'ANNA, 2002), que permite compreender o trabalho docente abrangendo uma rede de discursos que se responsabiliza pelos sentidos produzidos em/sobre uma dada atividade. É possível perceber que a sala de professores não se restringe a um espaço-tempo de descanso dos profissionais entre uma aula e outra, antes é cenário de elaboração de combinados de trabalho, realização de reuniões pedagógicas, produção de acordos coletivos, relativos não só a questões administrativas, como também sindicais, etc. Enfim, na sala de professores, saberes e práticas que se mostram inerentes ao magistério ganham consistência.

As hipóteses de leitura que vão sendo constituídas, bem como opções que se sustentam a partir delas se configuram em uma rede de diálogo produzidos pelo pesquisador. Se, classicamente, a imagem do trabalho docente que nos é apresentada aponta para as interações professor-aluno, ocorridas nos limites da sala de aula, a tentativa de pôr essas evidências em suspenso motiva-se, de um lado, por uma demanda que o pesquisador julga ser latente no cotidiano dos profissionais de educação: reclamações, comentários, reivindicações constantes apontam para uma angústia dos docentes frente ao prolongamento de sua jornada de trabalho para além dos limites da sala de aula. Por outro lado, as opções emergem ainda de um diálogo do pesquisador com o referencial das Ciências do trabalho, sobretudo com uma abordagem ergológica que privilegia o ponto de vista da atividade (FIGUEIREDO et al., 2004).

Desse modo, durante os oito meses em que transcorreram as observações na sala de professores, a referida pesquisa relata o papel importante do mural em tal contexto. Mais do que um recurso para "transmissão de informações", no mural circulavam textos que nos davam algumas pistas acerca das interações ocorridas naquele espaçotempo. Assim sendo, notícias de jornal, circulares, bilhetes, versículos bíblicos, entre outros textos, de alguma maneira, convocam seus leitores ao trabalho. Ao dirigir-se aos professores, esses textos falam deles e de seu trabalho, fazendo circularem expectativas de valores, produzindo sentido. 
Para a seleção do material que comporia o corpus de análise, adotaram-se os seguintes critérios: (i) textos que se dirigem explicitamente aos professores, ou seja, textos nos quais conste vocativo, pronome ou outro elemento que marque a inclusão do professor como interlocutor prioritário do referido texto; (ii) textos que tematizem o trabalho, mais especificamente o trabalho docente.

Encontra-se, em tal percurso, um desafio: o que fazer com textos tão distintos quanto uma notícia de jornal, um bilhete e uma circular? As diferenças entre eles eram marcantes: constroem-se lugares diversos para os coenunciadores de cada um dos textos, distinguemse no que tange à organização textual, possuem diferentes contextos de circulação, etc. $\mathrm{O}$ estranhamento diante de um material tão heterogêneo devia-se certamente à posição quase consensual em pesquisa de que o corpus constituído para fins de análise deve conter semelhanças ou pontos de interseção suficientes de modo a lograr trazer à luz um determinado conjunto de saberes acerca da realidade investigada. Percebe-se, no entanto, que era exatamente aquela variedade de elementos que caracterizava o mural como dispositivo de interação entre os profissionais que circulavam por aquele espaço. Nesse sentido, optou-se por agrupar os textos previamente selecionados em gêneros do discurso.

Nesse momento, alguns diálogos se estabelecem, por exemplo, com os manuais de metodologia que acabam por prescrever certas trajetórias e critérios em consonância com modelos de pesquisa que privilegiam percursos já dados. Ao optar por constituir o corpus de análise com textos que supostamente apontariam para uma dispersão tida tradicionalmente como indesejável nos modelos que se instituem em busca de regularidades, a pesquisa esboçou um caminho de um outro diálogo, agora com os modelos lineares de comunicação. Tomando como exemplo os versículos bíblicos, as notícias de jornal ou as resoluções, afixados no mural da sala de professores, é possível perceber que tais gêneros possuem contextos de circulação que chamaríamos "habituais", isto é, não têm no mural seu suporte privilegiado. A existência desses contextos "habituais" de circulação nos faria pensar que esses gêneros gozam de autonomia frente ao mural e que, por isso, seriam anteriores a ele. Nesse caso, o mural seria apenas uma moldura possível.

Outros gêneros, como o bilhete, por exemplo, fazem supor que sua existência depende do mural, ou seja, é posterior a ele. Tanto 
nesse caso como no anterior, a relação entre texto e mural se configuraria em um esquema linear.

Se notarmos o modelo de comunicação que subjaz à teoria do enunciado concreto de Bakhtin, perceberemos que, da perspectiva interacionista proposta por Bakhtin, rejeita-se a idéia de que primeiro se tem algo a dizer para, em seguida, se escolherem os meios utilizados em sua circulação. Por esse ponto de vista, o suporte seria apenas o meio escolhido, secundário frente ao que se teria a dizer.

A esse respeito, Maingueneau ressalta que "o mídium não é um simples 'meio', um instrumento para transportar uma mensagem estável: uma mudança importante do mídium modifica o conjunto de um gênero de discurso" (MAINGUENEAU, 2001, p. 72)

Consideramos assim que, quando alguém se propõe afixar um texto no mural, de certo modo, essa pessoa acaba por dialogar com alguns pressupostos acerca do trabalho docente. Quando alguém recorta uma notícia de um jornal para afixá-lo no mural, não o faz com qualquer texto. A escolha de um texto representa, em alguma medida, um diálogo com expectativas dos(as) profissionais. Afixar os textos no mural constitui uma relação de poder em que se produzem certos saberes sobre a prática docente.

A título de ilustração, quando se afixa um versículo bíblico no mural da sala de professores, vemos a enunciação proposta pelo mural deslocar-se entre o discurso administrativo e o religioso. Dessa forma, não se trata apenas de uma alteração no mídium. Tal deslocamento contribui para produzir sentidos sobre o trabalho dos professores, dialogando com certas expectativas e valores, que transitam entre o administrativo e o religioso, provocando afinidades e contraposições, enfim, polêmicas.

\subsection{Saberes privilegiados em concurso público para professores: seleção, diversos saberes conjugados}

Neste item, dialogamos com pesquisa cujo enfoque tratou de questionar que saberes sobre a prática docente são privilegiados em concursos públicos e que outros são silenciados. A motivação para o referido enfoque centra-se na tentativa de estabelecer as relações que se produzem entre conhecimentos formais e outros, que, embora nem sempre ganhem estatuto formal, emergem a partir da prática cotidiana 
no âmbito do magistério. Dessa forma, atentamos para o fato de que essa motivação põe em destaque diálogos de diferentes ordens que se estabelecem ao longo das diversas etapas de pesquisa em Análise do Discurso.

Uma das etapas que merece destaque trata da elaboração de critérios de delimitação do corpus de análise. Nesse sentido, a referida pesquisa destacou a insuficiência de se restringir às provas, considerando que essas são apenas um dos elos da cadeia que compõe esse particular processo vinculado a características específicas e restritas à admissão de um servidor público.

No contexto destas reflexões, cabe questionar que saberes o lingüista deve ativar para dar conta do desafio de compreender os diálogos que atravessam os três documentos: o Edital, o Manual do Candidato e a Prova. Vemos assim que se trata de saberes implicados na atividade de seleção que envolvem dimensões tradicionalmente reconhecidas como saberes que compõem o campo jurídico, administrativo, acadêmico, além de saberes compreendidos como "informais", ou seja, que correspondem à vivência cotidiana do candidato. É nesse momento que os referenciais mobilizados anteriormente tornam-se ferramentas efetivas no desafio nem sempre evidente de produzir cortes, aberturas, conexões entre saberes que se vêm mostrando como supostamente pertencentes a diferentes disciplinas.

Retomando as observações acerca da elaboração de critérios de definição do corpus de análise, diríamos que a referida pesquisa aponta para a tentativa de entender como os documentos constitutivos dos concursos públicos relacionam-se entre si, quais suas funções, por que existem, quais relações estabelecem, visando a uma melhor compreensão de como se instituem as relações de saber/poder que os atravessam. Vemos assim esboçar-se a necessidade de um investimento de pesquisa em que critérios elaborados do ponto de vista estritamente lingüístico se mostrariam insuficientes. É preciso constituir alianças entre campos diversos de saber.

Entre os diálogos que se mostraram produtivos, destaca-se a tentativa de compreensão dos modos de articulação dos textos na composição de um concurso público, do ponto de vista dos saberes jurídicos. A esse respeito, a pesquisa em questão apontou o edital como condição necessária para a realização de qualquer concurso público, ao 
recorrer à Constituição Federal. Nesse contexto, o edital funciona como contrato de adesão, cujas cláusulas são elaboradas unilateralmente pelo Estado e devem ser cumpridas por ambas as partes - Estado / candidato - a partir do momento em que são aceitas.

Com base nessas análises, o referido documento apresentase como prescrição de regras gerais e específicas para realização do concurso, pressupondo uma posição hierárquica estável do lugar do qual se enuncia, o lugar da lei. Esse dispositivo analítico que vai se desenvolvendo pelo pesquisador confronta-o, mais uma vez, com leituras que não se limitam à materialidade lingüística, mas a tomam como pistas para compreensão dos modos de construção das relações sociais restituindo sua complexidade. A partir desse ponto de vista, é possível pensar que o edital desenha-se como instrumento que serve ao mundo jurídico, para estabelecer as regras ao longo de um processo, determinando o que poderá ou não ser contestado pelo candidato; espécie de norte do que pode e não pode ser feito, que delimita os papéis espaço / tempo da interlocução. Existe em consonância com um contexto maior, orientado pela Constituição Federal e alguns decretos. Ou seja, é representante da voz do direito.

$\mathrm{Na}$ composição dos textos que constituem o concurso público, o manual é o único de que a realização de um certame pode prescindir. Se, do ponto de vista da ordem jurídica vigente, o manual não se configura como uma condição de realização da seleção, esse silenciamento nos textos da lei abre a possibilidade de elaboração de algumas hipóteses. Assim sendo, caberá aí questionar, por exemplo, que concursos optariam pelo uso do manual do candidato, ao lado do edital, e que outros concursos parecem prescindir deles.

Mesmo não sendo um documento previsto constitucionalmente, integra uma grande parte dos concursos que pressupõem grande número de candidatos. O manual estrutura-se em itens cuja função é organizar as informações, servindo como um roteiro de instruções, "um passo-a-passo" daquilo que o futuro professor precisa para participar do concurso e embora, muitas vezes, reproduza o edital, há nele um menor número de informações voltadas para a parte mais prática do concurso, o que marca a relação com o candidato, aqui mais próxima que a do edital. É a própria emergência, portanto, que colabora no sentido de pôr em evidência os diversos aspectos envolvidos na interação em análise. Se o manual reformula algumas 
informações constantes do edital, isso pode levar a supor que o último não está direcionado ao professor, provavelmente por possuir informações de cunho jurídico que "não dizem respeito a esse professor." É possível então identificar o candidato como coenunciador do manual e não do edital, co-enunciador este que precisa de uma outra linguagem que não a jurídica.

Especificamente com relação à análise das provas, pode-se afirmar que essas constituem um gênero que pressupõe normas a serem seguidas, assim como edital e manual. Conforme Giorgi (2005, p. 57) a importância de estudar o gênero provas se justifica por essas indicarem:

[...] no contexto atual de nossa realidade educacional, aquilo que os profissionais precisam saber. Funcionam como um padrão a ser seguido por aqueles que pretendem ingressar na rede pública, podendo, inclusive, influenciar cursos de formação, uma vez que a última seleção realizada sempre reflete não só o que se espera do professor naquele momento, mas também o que se antecipa para futuras seleções, sugerindo quais saberes devem ser privilegiados e reproduzidos. São, portanto, uma dupla memória que remete ao passado, reproduzindo e mantendo o que vem ou não sendo privilegiado, e aponta para o futuro, prescrevendo o que deve ou não continuar sendo considerado importante [...]

Assim, ao optar por uma compreensão conjunta dos textos envolvidos na seleção de professores na rede pública, essa investigação privilegiou, além das provas de língua estrangeira, o Edital e o Manual do Candidato, conferindo destaque ao diálogo existente entre eles e a necessária interlocução do pesquisador em Análise do Discurso com saberes jurídicos, administrativos, acadêmicos que, em tese, extrapolariam os limites dos estudos da linguagem.

\section{Conclusão}

Chegamos ao final do texto compartilhando com o leitor a questão que, a nosso ver, ainda vem suscitando polêmicas que julgamos produtivas. Trata-se de uma reflexão acerca da especificidade do ofício do lingüista frente a certo estilhaçamento das fronteiras tradicionalmente estabelecidas entre o lingüístico e seu entorno. 
Ao longo deste artigo, procuramos desenvolver algumas questões que nos permitam situar a organização dos saberes segundo uma lógica disciplinar como parte de um processo histórico. Vimos ainda que operações como a seleção, homogeneização e hierarquização de conteúdos de uma disciplina mostram-se presentes em diversas etapas do cotidiano de pesquisa do lingüista. Caberia, a nosso ver, procurar ativar dispositivos que contribuam no sentido de desmanchar as fronteiras que insistem em se mostrar "naturais" entre os diversos campos do saber.

Dessa forma, os diálogos com as pesquisas desenvolvidas por nós no âmbito do Programa de Pós-Graduação em Letras, área de concentração em Lingüística, da Universidade do Estado do Rio de Janeiro pretenderam pôr em análise alguns dos impasses diante dos quais nos vimos colocados em alguns momentos de nossas reflexões. No enfrentamento de tais impasses, é preciso compor um campo polêmico com o auxílio de outros saberes.

Diríamos assim que a especificidade do trabalho do lingüista parece residir não exatamente na exclusividade de um objeto de pesquisa, mas na opção prioritária da materialidade lingüística como entrada para análise da complexidade das ações do ser humano no mundo. Para assumir tal ponto de vista, estamos tentando rejeitar os especialismos que se tornaram hegemônicos entre os séculos XVIII e XIX, no ocidente, constituindo e valorizando dicotomias tais como aquelas que separariam os leigos dos especialistas, conhecimentos formais dos informais, ciência e política, entre outros.

Nossa especificidade residiria em, ao compartilhar um desafio comum com o conjunto das ciências humanas, oferecer diferentes formas, sempre provisórias, de apreensão dos modos de ser, pensar, agir e sentir no mundo que ganham consistência por meio da materialidade da linguagem.

\section{Referências bibliográficas}

BAKHTIN, M. A estética da criação verbal. Trad. Maria Ermantina Galvão. São Paulo: Martins Fontes, 2000. 
DEUSDARÁ, B. Imagens da alteridade no trabalho docente: enunciação e produção de subjetividade. 2006. Dissertação (Mestrado em Letras) Instituto de Letras, Universidade do Estado do Rio de Janeiro, Rio de Janeiro.

FOUCAULT, M. A arqueologia do saber. Trad. Luiz Felipe Baeta Neves. Rio de Janeiro: Forense Universitária, 2004.

. Em defesa da sociedade: curso no Collège de France (1975-1976). Trad. Maria Ermantina Galvão. São Paulo: Martins Fontes, 2002.

GIORGI, M. C. Seleção para a rede pública estadual de ensino: o que se espera do professor de Língua Estrangeira. 2005. Dissertação (Mestrado em Letras) - Instituto de Letras, Universidade do Estado do Rio de Janeiro, Rio de Janeiro.

.; DEUSDARÁ, P. Alianças e antagonismos: formas da alteridade no manual de concurso para professores e no folheto de propaganda política. In: SANT'ANNA, V; DEUSDARÁ, B. (Orgs.). Trajetórias em enunciação e discurso: conceitos e práticas. São Carlos: Claraluz, 2007.

MAINGUENEAU, D. Análise de textos de comunicacão. Trad. Cecília P. de Souza-e-Silva; Décio Rocha. São Paulo: Cortez, 2001.

ROCHA, D.; DAHER; D. C.; SANT'ANNA, V. Produtividade das investigações dos discursos sobre o trabalho. In: SOUZA-e-SILVA, C.; FAÏTA, D. (Orgs). Linguagem e trabalho: a construção de objetos de análise no Brasil e na França. São Paulo: Cortez, 2002.

ROCHA, M. L. da. Para além das evidências, dos princípios e dos valores instituídos no fazer pedagógico. Cadernos Transdisciplinares, Rio de Janeiro, 1998. 